\title{
Tourism: the current state and conditions for sustainable development of the hotel business
}

\author{
Elena Okhrimenko, and Alla Oshkordina* \\ Ural State University of Economics, 8 Marta/Narodnoy Voli St., 62/45, 620144 Ekaterinburg, Russia
}

\begin{abstract}
The article discusses the problems associated with the tourism industry and the hotel business during the pandemic. A study was carried out and relevant conclusions were presented on how the pandemic affected the hotel business in Europe and Russia. The authors examined and analyzed in detail the indicators of forecasts in the sphere of the Russian hotel business, particularly in the regions. The authors paid special attention to the study of open public spaces and conducted a detailed analysis, which made it possible to identify the opportunities for the development of the hotel business. In the article the main trends of a pandemic and post-pandemic are studied - the need to reinforce sanitary measures. The research focuses on identifying the features of the economic state of the regions during the pandemic. The authors developed and substantiated the areas that are relevant, useful and applicable for the hotel business; revealed the features of the process of restoration of the hotel business. Special attention is paid to the study of state support measures; the features of their further actualization for the development of the tourism industry are presented. The authors have proposed the ways to overcome the crisis, contributing to a slow, but accurate and safe recovery of the hotel business and an increase in demand.
\end{abstract}

\section{Introduction}

The hotel business at the present stage belongs to a developing industry that brings multimillion dollar profits around the world. The hotel business is a branch of the tourism business, which has a huge potential and makes a contribution to the development of the country's economy. The number of hotels is growing every year, which leads to fierce competition, which forces managers to resort to various methods of attracting customers. But there are situations that can completely change the hotel business.

In 2020, something happened that no manager was ready for, a situation that changed the entire hotel system in the world. The COVID-19 pandemic has made its own changes and affected all areas of business. Due to the spread of the virus and quarantine measures, more than half of the world's population is affected by lockdown; the closure of borders has led to stagnation of tourist activity, thereby leaving hotels without guests and money for profit, which has led to the closure of a large number of hotel businesses.

\footnotetext{
* Corresponding author: a12111la@yandex.ru
} 


\section{Materials and Methods}

The analysis of the issues related to the study of problems and the development of the tourism sector are reflected in the works of many Russian and foreign scientists. However, in the context of the pandemic, not enough research has been done in the field of the tourism industry. In addition, the issue of determining the state of the hotel business and description of the conditions for overcoming the crisis remain relevant.

It seems important to pay attention to the works in the field of domestic tourism development.

The works of researchers T.N. Grigorenko, L.N. [1] Kazmina [1], D.R. Makeeva [4], E.V. Semenova [7] are devoted to the analysis of priorities in the development of domestic tourism.

The works of V.I. Kruzhalina [3], N.V. Shabalina [3] present an in-depth study reflecting the state of the Russian tourism, problems and prospects for its development.

At the global level, special attention is paid to the study of such factors as the scientific and technological process, political stability and improvement of the quality of life of the population, since they also contribute to the further development of the tourism industry.

In many developed countries, tourism is the backbone of the economy. The foundation of the market, both qualitatively and quantitatively, is paid vacations for employees. In the modern world, the role of business travel and travel of persons of retirement age is huge, because travelling has become more accessible [9]. The coronavirus pandemic has made its own "adjustments", and negatively affected practically all areas of activity, including the tourism industry.

During the coronavirus pandemic, the tourism industry lost about $\$ 5$ trillion and more than 16 million jobs worldwide. The Turkish Hoteliers Association (TÜROB) noted that the occupancy rate of the largest hotels decreased by $70 \%$, as this indicator varies annually within $70-100 \%$, and in 2020 this figure dropped to $10-20 \%$, which led to large financial losses. The pandemic has also affected the hospitality industry in Europe, reaching 26.3\%, which in the lowest level since World War II. The average occupancy rate of European hotels annually varies between $60-80 \%$, compared to 2019 , the figure has decreased by $60 \%$. In March, the decline in profitability of London hotels reached $60 \%$, Paris hotels $69 \%$, Rome hotels - $86 \%$.

Even the largest chain hotels such as Marriott International, Radisson Hotels Group, Hilton Worldwide Holdings Inc., and Hyatt Hotels Corp. sent tens of thousands of their employees on unpaid leave or made them redundant due to the COVID-19 pandemic. Smaller hotels have had to resort to more drastic measures. Monty Bennett, CEO of Ashford Inc., that owns 130 hotels in the United States, said 95\% of the chain's 7,000 employees were dismissed and they will not be able to be back to work in the company in the near future. Pebblebrook HotelTrust CEO John Boretz had to close 54 hotels owned by the hotel operator and cut his 8,000 employees by $90-95 \%$ [2].

According to the head of the American Hotels and Accommodation Association, the pandemic has caused more economic damage than 9/11 and the 2008 recession combined. So, during negotiations with representatives of the American tourism industry and the US President Donald Trump, 250 billion US dollars of financial assistance was requested for possible ways to overcome the crisis that arose as a result of the pandemic.

The coronavirus pandemic has also negatively affected the situation in the hotel business in Russia. In 2019, the number of organizations in the Russian Federation decreased to 7.54 million, there was a decrease of $2 \%$, when the pandemic began to spread, negative dynamics persisted, the decrease in the number of enterprises reached $3 \%$. The coronavirus pandemic has accelerated the decline in the number of enterprises, with the most affected Moscow, St. Petersburg, Kabardino-Balkaria, Kaliningrad and Pskov regions, 
where in each region the number of operating enterprises decreased by $6-4 \%$. In some regions, there was a positive dynamics in the activity of the hotel business, namely in the Chukotka Autonomous Okrug, Buryatia, Crimea and Sevastopol, where the growth was 1$0.5 \%[5]$.

Leaders in the hospitality and restaurant industries asked for government support, and they themselves prepared measures to rebuild their businesses after the coronavirus crisis. After the weakening of lockdown measures, every fifth hotel in Russia was unable to restore its activities, and there is a risk that $40 \%$ of the hotel business will cease to exist. Small hotels, almost $22 \%$, were unable to restore their activities and continue providing services after the restrictions had been imposed, The most difficult situation is observed in large city hotels, since the average occupancy of hotels is $30 \%$, when usually this indicator varies within $65-75 \%$.

During the pandemic, it was important that the hospitality industry was advised to retain $2 / 3$ of the staff, as well as to send hotels with the most precarious situation on "tax holidays" until around the end of 2020. Before the outbreak of the COVID-19 pandemic, there were more than 21 thousand hotels in Russia with a total number of beds over 1.3 million. There were more than 2 thousand motels and hostels with a total number of beds of about 160 thousand. About 12 thousand enterprises fall under the definition of hotels with a total number of accommodations of more than 900 thousand beds. According to forecasts by experts in the hotel business, these figures next year will decrease by about a third. Despite the fact that in August 2020, hotel occupancy approached the pre-crisis level due to the surge in domestic tourism in the summer, the hotel business in Russia will fully recover no earlier than 2022-2023 [6].

The World Tourism Organization has prepared its recommendations to mitigate the economic impact of the pandemic on tourism.

The document was worked out with the help of the World Health Organization (WHO), International Civil Aviation Association (ICAO), International Maritime Aviation (IMO), Airports Council International (ACI), International Cruise Lines Association (CLIA), International Air Transport Association (IATA) and World Tourism and Travel Council (WTTC) [8].

Speaking the Ural region, it is worth noting that in Yekaterinburg, due to the measures taken, about $40 \%$ of hostels and mini-hotels that were part of the Association of Small Hotels and Hostels left the market due to bankruptcy. The business related to the resettlement of students, in particular foreign ones, was closed, and only 50-52 hostels remained to work.

At the moment, the "Liner" and "Panorama" hotels are closed in Yekaterinburg. The Liner will open only with the complete removal of restrictions on international transportation.

Thus, taking into the problems that the hotels and hostels of the city of Yekaterinburg faced, it is possible to proceed directly to changes in public spaces and services within organizations.

It is important to pay attention to the development of open public spaces. This is the main trend, with the help of which it is possible to develop not only the hotel business, but also to have a positive impact on the economy of the region. For example, co-working spaces, gastronomic markets, recreation and entertainment areas - these have become commonplace for residents of such a developing city as Yekaterinburg. Besides, many hotels are trying to keep up with the trends. Lobby bars are becoming multifunctional zones similar to street-food zones not only for city guests, but also for all city residents. This tendency, which is usual for us, has already begun to work in the opposite direction - now hotels delimit spaces, increase the distance between recreation areas, tables and strictly regulate the number of guests. 
Digitalisation of hotel services for guests is not new, but it is now starting to grow at a faster pace. Many hotels use tablets to check-in guests instead of the traditional front desk. This check-in system is used by AutographCollection hotels (Marriott side-brand) and Roomers.

The main trend of the pandemic and post-pandemic is strict sanitary measures. Today, new requirements for disinfection are being developed, which are reflected in the relevant standards.

It is also important to consider the use of materials in the decoration of the interiors of hotels, which can be easily disinfected.

New requirements are also imposed on the use of plumbing, for example, plumbing must have self-cleaning coatings and have an ultraviolet treatment module.

Finally, a very controversial solution for many hoteliers is the use of disposable and reusable tableware, since on the one hand, they should care for the environment, on the other hand, they should provide sanitary treatment.

During the pandemic, the opposite process is observed, associated with hygiene. Many hotels have now refused from the buffet and even standard dinners. Instead, some hotels use Room service, and, if possible, deliver food in vacuum packaging and plastic containers.

It is clear that the hotel business recovery process will take a long time, people will be afraid to check into rooms, and we can say that the hotel business will definitely not be the same. Marketers and hotel managers will refine their ideas as a result of the pandemic, which involve a minimum of contact with a large number of people.

Let's describe the ideas that are relevant, useful and applicable for the hotel business.

The first idea is a hotel that cleans itself: hygiene has become the most important point in the daily life of each of us in the era of coronavirus. Installing a modern ventilation and air disinfection system can become an everyday reality in all hotels, and robotic vacuum cleaners will reduce housekeeping hours. The maids will only come to change bed linen and hygiene items. Denmark has already developed a whole project for the introduction of modern ventilation, thanks to the ACT CleanCoat technology, the room is completely covered with an antibacterial substance that can destroy mold, microbes and allergens, and most importantly, it is completely safe. Another plus of this technology is that the antibacterial spray allows you to deodorize the air and works without replacement for a year. Thus, a modern ventilation system reduces the number of people in the room by $75 \%$.

The second idea is partial automation of hotels. Automation means that computers or robots perform the main responsibilities for check-in, delivering food, and so on. Selfcheckin counters will allow to enter your data yourself, while computers fully verify the authenticity of the documents provided, a person will be able to enter his room thanks to biometric data, where the system will compare the person's image with the image obtained during registration. At the self-registration counter, a person can independently choose the services they need: breakfast, spa, fitness room, etc. This is a complete absence of contacts with people, and the robot will bring you all the food.

But the automation of hotels does not mean staff reduction, there will be consumers who will be opponents of technology or those who are completely unfriendly with technology, for such people there will be the same staff who can be called by a special call button. Thus, no one will lose their jobs, and every consumer will be satisfied.

The third idea is a virtual art exhibition. Let's say you come to Paris and you really want to get into one of the largest and most popular art museums in the world - the Louvre, but you don't want to stand in long lines and somehow contact with people. Imagine that now every hotel is equipped with a VR box and VR glasses. This is a completely new service that you can purchase at the front desk. The virtual tour of the Louvre will be conducted live, thus you will feel as if you are really in the Louvre. This service can be provided in 
any city. For example, for Moscow, you can offer a VR tour of the Red Square or the Tretyakov Gallery, St. Petersburg can impress you with a tour of the Hermitage, Yekaterinburg will allow you to visit the Sevastyanov's house or be on the Vysotsky observation tower, and you needn't even leave your hotel room.

The fourth idea is disinfection stations. It is not just hand disinfection station, but a whole room disinfection with an odorless spray that does not harm the health, but protects from viruses for 30 minutes. Before checking in the hotel, each visitor will be guided through a completely unique station. The X-ray system and thermographic cameras will identify the infected by their body temperature, after which the hotel guests go through a disinfection station, which will protect you from all possible viruses at the time of your check-in.

The ideas presented above are quite feasible if there are investors who are ready to support the indicated ideas. Not every hotel will be able to apply and implement these measures in the next 2 years, since at present all efforts are aimed at overcoming the crisis. This is a long and difficult stage that requires clear strategic planning.

At the present stage, it is important to focus on the economic development of the regions, and especially on the legal regulation of economic relations, in particular, those connected with the development of tourism.

In fact, it is important to pay attention to the consequences of the crisis and that the period of the pandemic contributed not only to the identification of existing problems, but also to the discovery of new problems in the tourism industry. The development of tourism in Russia should be a priority. Particular attention should be paid to measures of state support and their further actualization for the development of the tourism industry.

The most important questions for market participants today are how to renew stable business relationships, how to develop a real strategy for coping with a pandemic, what ways exist to overcome the crisis in the tourism industry.

Of course, activation of one direction of development is ineffective, i.e. it is better to wait for the crisis to end, diversifying production and having different sources of income. In our opinion, it is necessary to develop new approaches related to the implementation of specific tours, to take into account the undeservedly forgotten directions in Russia.

Particular attention should be paid to the mandatory formation of a reserve fund in order to accumulate money in case of force majeure or unforeseen circumstances. This approach will enable the hotel business to relatively secure its activities, in other words, to have a safety bag, for a certain period of time, for example, if the arrival and accommodation of tourists is prohibited for some reasons.

The research results confirm the fact that it is important, especially now, to review and optimize the activities of travel companies. The market situation has changed dramatically, therefore, the goals, the tasks, and the planned sales have become irrelevant. In this regard, there is an urgent need to define new goals, objectives, as well as to change the conditions for the admission of workers and the organization of their work.

Let's pay special attention to the level of expenses of travel agencies. It is quite obvious that an unreasonable increase in expenses leads to bankruptcy, it is impossible to "reach" the situation of a cash gap. In this situation, it will be necessary to reduce the wages of employees, to fire them, which is unacceptable, or even to stop the work of the company for an indefinite period of time. All these situations will negatively affect not only the image of the travel company, but will also have a negative impact on the economy of the region.

It is a fact that some travel companies are trying to develop dubious and unjustified projects, investing large amount of money. This approach will be justified only if all costs are reasoned and supported by appropriate research. During a pandemic or a crisis, it is still advisable to minimize your expenses on projects that do not guarantee real income. 
During a pandemic, an emotional outburst, of course, in a negative sense, takes place. It is important not to succumb to panic, to look for appropriate ways out of the crisis using various approaches associated with the use of mergers and acquisitions strategies. In addition, when justifying one or another step regarding the merger, it is important to understand how such an approach will be mutually beneficial and making it possible to strengthen its position in the tourism services market.

\section{Results and Discussion}

The significance of the work lies in the fact that the proposed conclusions and detailed analysis of the problems within the framework of the current state of the hotel business are of particular interest for understanding the specific features of the hotel business, as well as taking appropriate measures from the state related to the support and further development of the Russian tourism industry.

It is important to take into account that as a result of the analysis carried out within the framework of the current situation associated with the pandemic, the work proposes and substantiates areas that are relevant, can be useful and effective for the hotel business.

\section{Conclusion}

Proceeding from the abovementioned, it is also necessary to focus on the development of new approaches in domestic tourism and set a new vector for the tourism industry. It is quite obvious that without support from the government, it is impossible to stimulate not only the development of the tourism industry, but also the implementation of relevant projects, taking into account the experience gained during the pandemic. State aid and support is, first of all, the provision of subsidies for socially significant areas of Russian economy.

Thus, within the framework of the development of the tourism industry, it is important, first of all, to introduce sound innovative projects and programs that will be aimed at satisfying the needs of consumers.

Despite the fact that the industry as a whole is facing a dramatic decrease in occupancy during the pandemic, hoteliers hope for a positive outcome, but it is important to consider all kinds of risks and the fact that the recovery process will be very long. Now the hotel business is gradually "recovering", but hotel occupancy will still remain low, since the trends are not yet the most positive, even if the tourist season starts, it will be later than usual. At the same time, one should not count on the massive activity of tourist demand. The above ways of overcoming the crisis will contribute to a slow but safe recovery of the hotel business, and new directions and ideas applied in the hotel business will increase demand.

\section{References}

1. T.N. Grigorenko, Bulletin of the National Academy of Tourism, 4, 14 (2015)

2. Annual report UNWTO, http://media.unwto.org/

3. V.I. Kruzhalin, K.V. Kruzhalin, N.V. Shabalin, Bulletin of the National Academy of Tourism, 1, 10 (2016)

4. D.R. Makeeva, Issues of the regional economy, 1, 39 (2015)

5. N.T. Margieva, Economics and Entrepreneurship, 10-1(63-1), 141 (2020)

6. Legal information for hotels during the coronavirus, https://hotelier.pro/ 
7. E.V. Semenova, N.V. Maslova, Bulletin of the National Academy of Tourism, 3, 34 (2016)

8. UNWTO calls for economic support through the travel and tourism sector, Daily electronic newspaper of the Russian Union of Travel Industry, https://ratanews.ru/

9. Travel \& Tourism Competitiveness Index//World Economic Forum, http://reports.weforum.org/ 